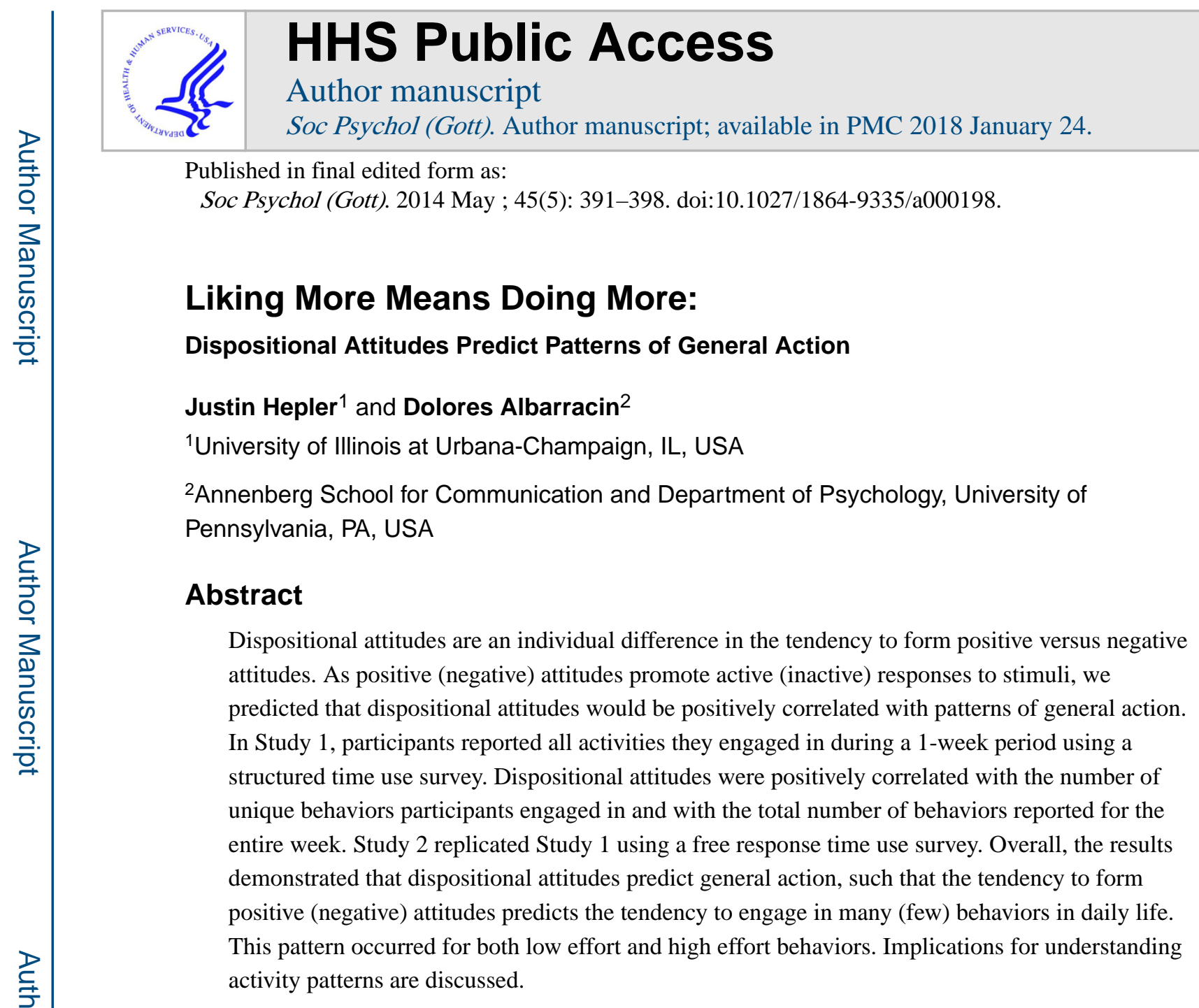

\title{
Keywords
}

action; attitudes; behavior; dispositional attitudes; motivation

People who like bicycles also tend to like architecture, receiving criticism, and taxes.

Dispositional attitudes, defined as an overall tendency to have positive or negative attitudes regardless of what stimuli are evaluated, imply that someone with a positive dispositional attitude is disposed to like diverse objects such as bicycles and taxes, whereas someone with a negative dispositional attitude is disposed to dislike these same stimuli (Hepler \& Albarracin, 2013a). An important function of attitudes is to guide behavior - the more someone likes an object, the more likely they are to engage in behaviors directed toward that object (Ajzen \& Fishbein, 2005). For example, positive (negative) attitudes toward condom use predict high (low) levels of condom use behavior (Albarracin, Johnson, Fishbein, \& Muellerleile, 2001). Because dispositional attitudes have no specific target by definition, they may correlate with the tendency to engage in behavior regardless of what behaviors are enacted. In other words, people who like many things may also do many things.

Justin Hepler, Department of Psychology, University of Illinois at Urbana-Champaign, 603 E. Daniel St., Champaign, IL 61820, USA, hepler1@illinois.edu. 


\section{Attitudes and Activity}

An attitude is defined as an individual's overall evaluation of a target (e.g., whether someone associates positive or negative affect with a behavior, event, issue, object, person, etc.; Albarracin \& Vargas, 2010). Although attitudes do not always predict behavior (Ajzen \& Fishbein, 2005), when they do predict behavior, positive (negative) attitudes are typically associated with active (inactive) responses to stimuli. For example, using evaluative conditioning to pair behaviors such as cleaning with positive (negative) affect increases (decreases) subsequent pursuit of the conditioned behaviors (Aarts, Custers, \& Holland, 2007; Custers \& Aarts, 2005a, 2005b). Thus, positive (negative) attitudes are frequently associated with action (inaction) directed toward the attitude's target. Dispositional attitudes represent the tendency to have positive or negative attitudes toward stimuli in general (Hepler \& Albarracin, 2013a), and thus we predict that positive (negative) dispositional attitudes will be related with an increased (decreased) pursuit of general activity.

\section{Predicting Behavior From Attitudes}

Although people's behaviors are frequently related to their attitudes, past research has identified a variety of factors that moderate the relation between attitudes and behaviors (Borgida \& Campbell, 1982; Fazio \& Zanna, 1978a, 1978b; Glasman \& Albarracin, 2006; Kraus, 1995; Schwartz, 1978; Sivacek \& Crano, 1982). Of relevance for the present research, the compatibility principle of behavior prediction states that for psychological constructs to accurately predict behaviors, the constructs and behaviors must match on their level of specificity versus generality (Ajzen \& Fishbein, 1977, 2005). For example, a measure of "attitudes toward having a child in the next two years" strongly predicts actually having a child in the next two years $(r=.54)$, whereas a measure of "attitudes toward children" does not ( $r=-.01$ ) (Davidson \& Jaccard, 1979). Similarly, a broad measure of "attitudes toward religion" is a poor predictor of specific target behaviors such as church donations (average correlation with individual religious behaviors, $r=.14$ ), but it is an excellent predictor of broad behavioral aggregates that combine multiple specific behaviors such as church donations and church attendance (correlation with an aggregate of 100 religious behaviors, $r=.64$ ) (Fishbein \& Ajzen, 1974). As dispositional attitudes represent the most general form an attitude can take (i.e., simply liking or disliking, regardless of the attitude-object), they should be expected to predict the most general form of behavior namely, whether or not one pursues activity.

Of relevance, individuals are often motivated to be active or inactive regardless of what behaviors are pursued, which is known as general action motivation (Albarracin et al., 2008; Albarracin, Hepler, \& Tannenbaum, 2011). General action motivation promotes increased behavioral activity across seemingly unrelated target behaviors, such as exercise (Hepler, Wang, \& Albarracin, 2012), impulsive motor behaviors (Hepler, Albarracin, McCulloch, \& Noguchi, 2012; Hepler \& Albarracin, 2013b), participation in politics (Noguchi, Handley, \& Albarracin, 2011), food consumption (Albarracin et al., 2008; Albarracin, Wang, \& Leeper, 2009), reading (Albarracin \& Hart, 2011; Hart \& Albarracin, 2012), effortful resistance to persuasive messages (Albarracin \& Handley, 2011), and effort directed toward cognitive tasks (Albarracin et al., 2008; Gendolla \& Silvestrini, 2010; Laran, 2010; Silvestrini \& 
Gendolla, 2013). Further, individuals differ in their tendencies to pursue general action, such that some people prefer to be very active whereas others prefer to be relatively inactive (McCulloch, Li, Hong, \& Albarracin, 2012; Zell et al., 2013). Based on the compatibility principle, a very general attitude would be required to predict variation in general action. Dispositional attitudes satisfy this criterion because they represent whether individuals like or dislike stimuli in general, regardless of any stimulus-specific information. Therefore, the behavioral outcome most relevant for dispositional attitudes should be a measure of the number of behaviors in which people engage (i.e., general action).

\section{Action Versus Effort}

An important distinction is that between action and effort. For the present purposes, we will define action as any form of behavior regardless of how effortful that behavior is, whereas we will define effort as the mobilization and investment of resources that are associated with an action (e.g., Brehm \& Self, 1989). Thus, playing sports and talking on a telephone are equally active behaviors because both involve doing something rather than nothing. In contrast, playing sports is a much more effortful behavior than a telephone conversation because the former requires a much greater expenditure of physiological resources than the latter. Research on the association between attitudes and behavior has traditionally conceptualized behavior from the perspective of "activity" rather than "effort." Thus, attitudes predict both high effort behaviors such as sports (Graham, Sirard, \& NeumarkSztainer, 2011) as well as low effort behaviors such as reading information (Hart et al., 2009). Therefore, we predict that dispositional attitudes will be positively related with the number of behaviors people pursue, and this should be true for both low effort and high effort behaviors'.

\section{Overview}

We examined whether dispositional attitudes correlate with general action based on the assumption that dispositional attitudes motivate behavior. Two studies were conducted to investigate this hypothesis. In Study 1, participants recorded all activities in which they engaged over a 1-week period using a structured time use survey and completed a measure of dispositional attitudes. Study 2 replicated and extended Study 1 using a free response time use survey. For both studies, number of reported activities over the 1-week period was regressed onto dispositional attitudes to examine whether dispositional attitudes predicted general action.

\section{Study 1 \\ Method}

Participants-Participants $(N=100)$ were recruited online using Amazon's Mechanical Turk website. Our sample size was designed to include 100 participants, and data collection was terminated when this criterion was met; the data were not analyzed until all participants had completed the study. Participants were paid $\$ 0.10$ to complete the study. The age of respondents ranged from 18 to 59, with a mean of 30.63 years ( $S D=8.58$ years). In this sample, $46 \%$ of respondents were female, $76 \%$ had a bachelor's degree or higher, and the 
modal income category was $\$ 0-\$ 24,999$. The sample was $60 \%$ Indian, $22 \%$ Caucasian, $17 \%$ Non-Indian Asian, and $1 \%$ other.

Procedure-Participants were informed that the study concerned personality, attitudes, and daily activity habits. Participants first completed the American Time Use Survey (ATUS), which measures how people spend their time on a day-today basis (Shelley, 2005). The ATUS lists 17 activity categories such as educational activities, government services and civic obligations, and sports. Below each category label, participants are provided with example behaviors for that category (e.g., "Volunteer activity examples: Any not-for-profit work you do through an organization such as Big Brothers Big Sisters [BBBS]"). For each category, participants indicated "During the last 7 days, on how many days did you do this?" (using a scale from 0 to 7 days) and "How much time did you usually spend doing this on one of those days?" (responses were entered in minutes). Although participants were recruited online and participation was not restricted to the US, the ATUS is still a suitable time use measure because none of the behavioral categories are unique to US culture even though a few of the specific examples may be (e.g., BBBS is a US-based volunteer organization). Further, the ATUS provides a general description of each behavioral category in addition to specific examples - for example, when describing volunteer activities, the survey states "Any not-for-profit work you do" in addition to providing the specific example of BBBS. Further, many Americans may actually be unfamiliar with the specific behavioral examples provided in the ATUS such as BBBS, and thus non-American English speaking participants should not have any more difficulties responding to the survey than US samples. Indeed, no participants reported difficulty understanding the questionnaire, and responses indicated that participants completed the questionnaire appropriately.

Participants then completed the Dispositional Attitude Measure (DAM), which has participants report attitudes toward 16 independent attitude-objects such as architecture, bicycles, and taxes (Hepler \& Albarracin, 2013a). Responses are averaged together to yield a single index of a participant's overall tendency to have positive or negative attitudes toward stimuli, regardless of what those stimuli are.

The survey included four "attention check" questions that read: "This question checks whether you are skipping questions. Select the middle option." These questions were randomly inserted throughout the questionnaires, and the response option to be selected varied across each question. Five respondents failed at least two attention check questions, and their data were excluded from analyses. Therefore the final sample size is 95 (the results were unchanged when the five excluded participants were retained).

\section{Results and Discussion}

First, we calculated the number of distinct behavioral categories out of 17 in which participants engaged at least once during the week (this theoretically ranges between 0 and 17). Number of activities $(M=13.51, S D=2.79)$ was positively correlated with dispositional attitudes $(M=4.64, S D=0.82, a=.82), r=.38, p<.001$. These results confirm the hypothesis that dispositional attitudes are positively related with general action patterns. 
Total Active Time-It is possible that people with positive dispositional attitudes simply spend more time being awake rather than asleep, and that this difference accounts for the observed effects. As the ATUS does not include a category for sleep, we calculated the total time per week participants engaged in behaviors. This was done by multiplying the number of days/week by minutes/day for each behavioral category and summing these values across all 17 categories. Total reported time throughout the week $(M=113.90 \mathrm{hr}, S D=88.64 \mathrm{hr}$ ) was uncorrelated with dispositional attitudes, $r=.00, p=.98$. Further, when controlling for total active time reported throughout the week in a regression analysis, dispositional attitudes were still significantly associated with number of activities $(\beta=.38, p<.001)$.

High Versus Low Effort Activities-Some ATUS categories are more effortful than others. For example, the category sports is higher effort than the category telephone calls. To investigate whether dispositional attitudes predict action independently of associated effort, we divided the ATUS behaviors into low and high effort categories using effort estimates derived from previous research. Specifically, researchers have calculated the average metabolic energy cost of engaging in each ATUS category via a measure known as the metabolic equivalent (MET), which represents the energy cost of an activity relative to rest (Tudor-Locke, Washington, Ainsworth, \& Troiano, 2009). The ATUS is a hierarchical measure containing the 17 tier one categories used in the present research along with 438 tier two categories that are nested within the tier one categories, and previous research has calculated MET estimates for the tier two categories (Tudor-Locke et al., 2009). As we did not include tier two categories in the present research, we created MET estimates for the tier one categories by simply averaging the MET estimates for each of the tier two categories nested within each tier one category (see Table 1). Next, we classified ATUS categories into high and low effort groups based on whether their MET estimate was above or below the average MET $\left(M_{\mathrm{MET}}=2.03, S D_{\mathrm{MET}}=.57\right.$; the results are the same when using the median). Dispositional attitudes were positively correlated with the number of low effort categories $(M=7.61, S D=1.65)$ and high effort categories $(M=5.89, S D=1.30)$ participants engaged in during the week, $r=.36, p<.001$ and $r=.35, p<.001$, respectively. Further, these correlations were not significantly different from each other, $z=.08, p=.94$. Thus, dispositional attitudes are related to patterns of activity independently of the effort associated with the activities. In other words, people who like more things do more things regardless of how effortful those things are.

\section{Conclusions}

Study 1 demonstrated that dispositional attitudes are positively related with action, such that individuals with positive dispositional attitudes engage in more behaviors throughout a typical week compared to individuals with negative dispositional attitudes. Further, this was true for both low effort and high effort behaviors.

\section{Study 2}

Study 2 was conducted with four primary objectives. First, participants in Study 1 were forced to use the behavioral categories provided to them in the ATUS. However, participants may have engaged in behaviors they could not fit into one of these categories, and thus some 
behaviors may have gone unreported. Study 2 therefore uses a free response time use survey to address this limitation. Second, time spent sleeping was not measured in Study 1, but sleep could be analyzed to bolster the claim that dispositional attitudes and general action are not simply related due to dispositional attitudes being related to hours spent awake versus asleep. Third, although a measure of objective effort (MET) was unrelated to dispositional attitudes in Study 1, it is possible that a measure of subjective effort would be related. Therefore, Study 2 has participants report how subjectively difficult each of their own behaviors felt to them. Fourth, dispositional attitudes are related to variety seeking (Hepler \& Albarracin, 2013a observed a correlation of $r=.20$ ), and it is therefore important to examine whether dispositional attitudes and action are still related when controlling for variety seeking motivation; Study 2 therefore includes a measure of variety seeking.

\section{Method}

Participants-We conducted a power analysis to determine an appropriate sample size for this study. In Study 1, the smallest correlation of interest was $r=.35$ (the correlation between dispositional attitudes and high effort behaviors). To detect a significant correlation of at least $r=.35$ with a power of .99 and an alpha rate of .05 , a sample size of at least 134 is required. Therefore, we recruited 150 participants online using Amazon's Mechanical Turk website; the data were not analyzed until all participants had completed the study. Participants were paid $\$ 0.30$ to complete the study. The age of respondents ranged from 18 to 65 , with a mean of 31.86 years ( $S D=10.47$ years). In this sample, $37 \%$ of respondents were female, $77 \%$ had a bachelor's degree or higher, and the modal income category was $\$ 0-\$ 24,999$. The sample was $75 \%$ Indian, $16 \%$ Caucasian, $6 \%$ Non- Indian Asian, and 3\% other. The survey included four "attention check" questions similar to Study 1. Eight respondents failed at least two attention check questions, and their data were excluded from analyses. Therefore the final sample size is 142 (the results were unchanged when the eight excluded participants were retained).

Procedure-The procedure was similar to Study 1 with the following exceptions. For the time use survey, participants were provided with a table that contained 25 rows, and they were instructed to report all behaviors they engaged in during the past seven days. Each row contained (a) a blank space in which participants could type a description of the activity, (b) a box to select the number of days (out of 7) they engaged in that behavior, (c) boxes to select how many hours and minutes they engaged in that behavior on a typical day they did it, and (d) a box to select how much effort the behavior required using a response scale from one (= required little or no effort) through four (= required an average amount of effort) to seven (= required a great amount of effort). Participants were instructed to group their behaviors however they saw fit when reporting them, and they were told they did not need to use the entire table if it was unnecessary. The first row was always filled in for participants with the activity of sleep. After the time use survey, participants completed the DAM, a 10item individual difference measure of variety seeking from the International Personality Item Pool (Goldberg et al., 2006), and a demographics form. The variety seeking measure asks questions such as "I prefer variety to routine" and "I love to think up new ways of doing things," and participants' responses were recorded using a scale from 1 (= disagree strongly) to 7 (= agree strongly). 


\section{Results and Discussion}

The number of activities reported on the time use survey $(M=10.20, S D=5.23)$ was positively correlated with dispositional attitudes $(M=4.10, S D=0.78, a=.77), r=.26, p$ $=.001$. Further, dispositional attitudes were uncorrelated with nightly sleep $(M=7.33 \mathrm{hr}, S D$ $=2.65 \mathrm{hr})$ and total time engaging in behavior throughout the week $(M=163.77 \mathrm{hr}, S D=$ $48.74 \mathrm{hr}), r=.04, p=.61$ and $r=.14, p=.10$, respectively. Dispositional attitudes and variety seeking ( $M=5.33, S D=0.90, \mathrm{a}=.84)$ were positively correlated, $r=.23, p=.007$. However, dispositional attitudes were still significantly associated with number of activities when controlling for variety seeking $(\beta=.26, p=.002)$, total active time $(\beta=.21, p=.007)$, sleep $(\beta=.27, p=.001)$, and all three variables simultaneously $(\beta=.19, p=.01)$.

The average self-reported effort associated with behaviors $(M=3.41, S D=1.13)$ was uncorrelated with dispositional attitudes, $r=.05, p=.56$. We also classified all behaviors as low effort or high effort based on whether participants rated the behavior below or above four on the effort scale (four was the midpoint of the scale and was labeled with the phrase required an average amount of effort). The average number of low effort behaviors for each participant was $5.46(S D=4.46)$, and the average number of high effort behaviors for each participant was $4.54(S D=3.45)$. Dispositional attitudes were positively correlated with low effort and high effort behaviors, $r=.18, p=.03$ and $r=.17, p=.04$, respectively. Further, these correlations were not significantly different from each other, $z=.09, p=.93$.

Therefore, these results replicate Study 1 while demonstrating several important points. First, the association between dispositional attitudes and activity remained when participants self-categorized their behaviors in a free response format. Second, dispositional attitudes were unrelated to total time spent being active versus asleep. Third, dispositional attitudes were related to low and high effort behavior when effort was measured subjectively. Fourth, the association between dispositional attitudes and activity was not accounted for by personality differences in variety seeking.

\section{General Discussion}

Although attitudes do not always predict behavior, when they do predict behavior, positive attitudes tend to predict action, whereas negative attitudes tend to predict inaction (Aarts et al., 2007; Borgida \& Campbell, 1982; Custers \& Aarts, 2005a, 2005b; Fazio \& Zanna, 1978a, 1978b; Glasman \& Albarracin, 2006; Kraus, 1995; Schwartz, 1978; Sivacek \& Crano, 1982). Because dispositional attitudes reflect an overall tendency to possess positive versus negative attitudes in general, we predicted and found that dispositional attitudes were positively related with patterns of general action - people who like many (few) things also do many (few) things. Therefore, people with high (low) dispositional attitudes tend to pursue high (low) levels of activity.

The present research has implications for understanding the antecedents of general action patterns. Specifically, some individuals may pursue large amounts of activity because they develop and maintain positive attitudes toward most stimuli they encounter. General action motivation is typically conceptualized as a desire to be active or inactive regardless of what behaviors are pursued or foregone (Albarracin et al., 2008, 2011). However, some people 
may be more active than others not because they want to be active per se but because they identify a large number of specific behaviors in which they want to engage. Thus, patterns of general action can occur for top-down reasons ("I want to be active, so I will do a lot of things") or bottom-up reasons ("I like doing a lot of different things, so I will do them all"). Prior research has not made this distinction, but the present results demonstrate that patterns of general action may occur for reasons other than the desire to be active versus inactive.

It is possible that dispositional attitudes cause behavioral activity - that is, by experiencing positive (negative) attitudes whenever stimuli are encountered, people with positive (negative) dispositional attitudes may be motivated to engage in (avoid) behaviors related to those stimuli. However, it is also possible that behavioral activity causes dispositional attitudes. For example people who are very active (inactive) may decide via self-perception that they must like (dislike) many things, or else they would not do so many (few) things. In this vein, it is possible that completing a time use survey could prime a self-concept related to dispositional attitudes, and participants may consequently change their DAM responses after this concept is primed; as the present research did not restrict participants from modifying survey responses after completing each form, the present studies cannot rule out this possibility. Additionally, participants may possess lay theories that if they like many (few) things, they should be doing many (few) things with their time, and they may lie about their activities or attitudes to appear coherent in their responses. To explore these alternate causal models, future research could attempt to manipulate state levels of dispositional attitudes, state levels of activity, lay theories of activity-attitude relations, and motivation to appear coherent in order to further refine the causal processes responsible for the observed relations.

The present research also found that dispositional attitudes are positively related to behavioral activity for both low effort and high effort behaviors. This is consistent with prior attitude research because even for relatively inactive behaviors, positive attitudes should promote behavioral engagement (e.g., if you like television, you watch television). That is, a positive attitude toward a target should lead to pursuit of that target, even if it is a low effort or inhibitory behavior. Thus, the present results are compatible with research demonstrating that positive moods can lead to the pursuit of low effort "inaction" behaviors if the concept of inaction is primed (e.g., Albarracin \& Hart, 2011).

\section{Relations Between Activity and Affect}

Positive and negative affect have complex relations with behavior (e.g., Clore \& Huntsinger, 2009; Lang, 1995), and both types of affect have been shown to motivate action and inaction under different conditions (e.g., Aarts, Custers, \& Veltkamp, 2008; Cacioppo, Gardner, \& Berntson, 1999; Carver \& Harmon-Jones, 2009; Carver \& Scheier, 1990; Clore, 1994; Fredrickson, 1998, 2001; Hart \& Gable, 2013). For example, certain negative affective states can lead to action (e.g., anger can motivate attack behavior), whereas others can lead to inaction (e.g., sadness can lead to the cessation of behavior). Similarly, certain positive affective states can lead to action (e.g., interest and excitement can lead to approach), whereas others can lead to inaction (e.g., satisfaction and contentment can lead to rest). 
In the present research, we demonstrated a clear association between positive (negative) affect and action (inaction). Specifically, people with positive (negative) dispositional attitudes engaged in more (fewer) behaviors throughout a typical week. The direction of this association (i.e., attitudes positively predicting action) is consistent with prior research on attitude-behavior relations, which demonstrates that the more people like (dislike) something, the more (less) likely they are to do it (Ajzen \& Fishbein, 1977, 2005; Borgida \& Campbell, 1982; Fazio \& Zanna, 1978a, 1978b; Fishbein \& Ajzen, 1974; Glasman \& Albarracin, 2006; Kraus, 1995; Schwartz, 1978; Sivacek \& Crano, 1982). Further, the direction of this relation is consistent with contemporary theories of how affect is related to action (e.g., Clore \& Huntsinger, 2009). Specifically, when affect is construed to represent the value of a goal or stimulus, positive affect promotes active pursuit of the goal, whereas negative affect promotes non-pursuit. In contrast, when affect is construed to represent one's progress toward goal attainment, positive affect promotes a cessation of action (i.e., inaction), whereas negative affect promotes a continuance of action (e.g., Fishbach \& Labroo, 2007; Martin, Achee, Ward, \& Wyer, 1993). For example, people who are working on a task and consider the question "Am I enjoying this task?" (i.e., they consider their attitude toward the task) continue working on the task longer if they are in a positive mood compared to a negative mood, whereas people who are working on the same task and consider the question "Have I done enough for this task?" continue working on the task longer if they are in a negative mood compared to a positive mood (Martin et al., 1993).

As attitudes represent an association of a stimulus with affect (e.g., Fazio, 2007), attitudes should generally signal the value of a stimulus to the individual who holds the attitude. Thus, based on theories that relate affect and activity, positive affect in the form of attitudes should promote action, whereas negative affect in the form of attitudes should promote inaction, which is what our results demonstrate. However, positive and negative affect in other forms will not always promote action and inaction, respectively. Indeed, as mentioned above, the association between affect and activity is complex (Clore \& Huntsinger, 2009; Lang, 1995), and both types of affect can promote either action or inaction under various conditions. However, the present results demonstrate that positive (negative) affect in the form of attitudes can predict action (inaction).

\section{Concluding Remarks}

The present research demonstrated an important correlate of dispositional attitudes namely, behavioral activity. People with positive dispositional attitudes are disposed to be relatively active in their daily lives, whereas people with negative dispositional attitudes are disposed to be relatively inactive. These findings contribute to the existing literature by demonstrating important behavioral correlate of dispositional attitudes and by identifying a previously overlooked antecedent for general action motivation. To conclude, people who like more things also do more things in the course of their daily lives.

\section{References}

Aarts H, Custers R, Holland RW. The nonconscious cessation of goal pursuit: When goals and negative affect are coactivated. Journal of Personality and Social Psychology. 2007; 92:165-178. [PubMed: 17279843] 
Aarts H, Custers R, Veltkamp M. Goal priming and the affective-motivational route to nonconscious goal pursuit. Social Cognition. 2008; 26:555-577.

Ajzen I, Fishbein M. Attitude-behavior relations: A theoretical analysis and review of empirical research. Psychological Bulletin. 1977; 84:888-918.

Ajzen, I., Fishbein, M. The Influence of attitudes on behavior. In: Albarracin, D.Johnson, B., Zanna, MP., editors. The handbook of attitudes. Mahwah, NJ: Lawrence Erlbaum Associates Publishers; 2005. p. 173-221.

Albarracin D, Handley IM. The time for doing is not the time for change: Effects of general action and inaction goals on attitude retrieval and attitude change. Journal of Personality and Social Psychology. 2011; 100:983-998. [PubMed: 21639651]

Albarracin D, Handley IM, Noguchi K, McCulloch KC, Li H, Leeper J, Hart W. Increasing and decreasing motor and cognitive output: A model of general action and inaction goals. Journal of Personality and Social Psychology. 2008; 95:510-523. [PubMed: 18729691]

Albarracin D, Hart W. Positive mood + action = negative mood + inaction: Effects of general action and inaction concepts on decisions and performance as a function of affect. Emotion. 2011; 11:951957. [PubMed: 21859209]

Albarracin D, Hepler J, Tannenbaum M. General action and inaction goals: Their behavioral, cognitive, and affective origins and influences. Current Directions in Psychological Science. 2011; 20:119-123. [PubMed: 23766569]

Albarracin D, Johnson BT, Fishbein M, Muellerleile PA. Theories of reasoned action and planned behavior as models of condom use: A meta-analysis. Psychological Bulletin. 2001; 127:142-161. [PubMed: 11271752]

Albarracin, D., Vargas, P. Attitudes and persuasion: From biology to social responses to persuasive intent. In: Fiske, ST.Gilbert, DT., Lindzey, G., editors. The handbook of social psychology. Hoboken, NJ: Wiley; 2010. p. 394-427.

Albarracin D, Wang W, Leeper J. Immediate increases in eating following exercise promotion messages. Obesity. 2009; 17:1451-1452. [PubMed: 19247284]

Borgida E, Campbell B. Belief relevance and attitude-behavior consistency: The moderating role of personal experience. Journal of Personality and Social Psychology. 1982; 42:239-247.

Brehm JW, Self EA. The intensity of motivation. Annual Review of Psychology. 1989; 40:109-131.

Cacioppo JT, Gardner WL, Berntson GG. The affect system has parallel and integrative processing components: Form follows function. Journal of Personality and Social Psychology. 1999; 76:839855.

Carver CS, Harmon-Jones E. Anger is an approach-related affect: Evidence and implications. Psychological Bulletin. 2009; 135:183. [PubMed: 19254075]

Carver CS, Scheier MF. Origins and functions of positive and negative affect: A control-process view. Psychological Review. 1990; 97:19-35.

Clore, GL. Why emotions are felt. In: Ekman, P., Davidson, R., editors. The nature of emotion: Fundamental questions. New York, NY: Oxford University Press; 1994. p. 103-111.

Clore GL, Huntsinger JR. How the object of affect guides its impact. Emotion Review. 2009; 1:39-54. [PubMed: 25431618]

Custers R, Aarts H. Beyond accessibility: The role of affect and goal discrepancies in implicit processes of motivation and goal-pursuit. European Review of Social Psychology. 2005a; 16:257300.

Custers R, Aarts H. Positive affect as implicit motivator: On the nonconscious operation of behavioral goals. Journal of Personality and Social Psychology. 2005b; 89:129-142. [PubMed: 16162049]

Davidson AR, Jaccard JJ. Variables that moderate the attitude-behavior relation: Results of a longitudinal survey. Journal of Personality and Social Psychology. 1979; 37:1364-1376.

Fazio RH. Attitudes as object-evaluation associations of varying strength. Social Cognition. 2007; 25:603-637. [PubMed: 19424447]

Fazio RH, Zanna MP. Attitudinal qualities relating to the strength of the attitude-behavior relationship. Journal of Experimental Social Psychology. 1978a; 14:398-408. 
Fazio RH, Zanna MP. On the predictive validity of attitudes: The roles of direct experience and confidence. Journal of Experimental Social Psychology. 1978b; 46:228-243.

Fishbach A, Labroo AA. Be better or be merry: How mood affects self-control. Journal of Personality and Social Psychology. 2007; 93:158-173. [PubMed: 17645393]

Fishbein M, Ajzen I. Attitudes towards objects as predictors of single and multiple behavioral criteria. Psychological Review. 1974; 81:59-74.

Fredrickson BL. What good are positive emotions? Review of General Psychology. 1998; 2:300-319. [PubMed: 21850154]

Fredrickson BL. The role of positive emotions in positive psychology: The broaden-and-build theory of positive emotions. American Psychologist. 2001; 56:218-226. [PubMed: 11315248]

Gendolla GHE, Silvestrini N. The implicit "go": Masked action cues directly mobilize mental effort. Psychological Science. 2010; 21:1389-1393. [PubMed: 20861511]

Glasman LR, Albarracin D. Forming attitudes that predict future behavior: A meta-analysis of the attitude-behavior relation. Psychological Bulletin. 2006; 132:778-822. [PubMed: 16910754]

Goldberg LR, Johnson JA, Eber HW, Hogan R, Ashton MC, Cloninger CR, Gough HC. The International Personality Item Pool and the future of public-domain personality measures. Journal of Research in Personality. 2006; 40:84-96.

Graham DJ, Sirard JR, Neumark-Sztainer D. Adolescents' attitudes toward sports, exercise, and fitness predict physical activity 5 and 10 years later. Preventive medicine. 2011; 52:130-132. [PubMed: 21130803]

Hart W, Albarracin D. Craving activity and losing objectivity: Effects of general action concepts on approach to decision-consistent information. Social Psychological and Personality Science. 2012; 3:55-62.

Hart W, Albarracin D, Eagly AH, Brechan I, Lindberg MJ, Merrill L. Feeling validated versus being correct: A meta-analysis of selective exposure to information. Psychological Bulletin. 2009; 135:555. [PubMed: 19586162]

Hart W, Gable PA. Motivating goal pursuit: The role of affect, motivational Intensity, and activated goals. Journal of Experimental Social Psychology. 2013; 49:922-926.

Hepler J, Albarracin D. Attitudes without objects: Evidence for a dispositional attitude, its measurement, and its consequences. Journal of Personality and Social Psychology. 2013a; 104:1060-1076. [PubMed: 23586409]

Hepler J, Albarracin D. Complete unconscious control: Using (in)action primes to demonstrate completely unconscious activation of inhibitory control mechanisms. Cognition. 2013b; 128:271279. [PubMed: 23747649]

Hepler J, Albarracin D, McCulloch KC, Noguchi K. Being active and impulsive: The role of goals for action and inaction in self-control. Motivation and Emotion. 2012; 36:416-424. [PubMed: 23766548]

Hepler J, Wang W, Albarracin D. Motivating exercise: The interactive effect of general action goals and past behavior on physical activity. Motivation and Emotion. 2012; 36:365-370. [PubMed: 23606776]

Kraus SJ. Attitudes and the prediction of behavior: A meta-analysis of the empirical literature. Personality and Social Psychology Bulletin. 1995; 21:58-75.

Lang PJ. The emotion probe: Studies of motivation and attention. American Psychologist. 1995; 50:372. [PubMed: 7762889]

Laran J. The influence of information processing goal pursuit on post decision affect and behavioral intentions. Journal of Personality and Social Psychology. 2010; 98:16-28. [PubMed: 20053028]

Martin LL, Achee JW, Ward DW, Wyer RS. Mood as input: People have to interpret the motivational implications of their moods. Journal of Personality and Social Psychology. 1993; 64:317-326.

McCulloch KC, Li H, Hong S, Albarracin D. Naïve definitions of action and inaction: The continuum, spread, and valence of behaviors. European Journal of Social Psychology. 2012; 42:227-234. [PubMed: 23487013]

Noguchi K, Handley IM, Albarracin D. Participating in politics resembles physical activity: General action patterns in international archives, United States archives, and experiments. Psychological Science. 2011; 22:235-242. [PubMed: 21177515] 
Schwartz SH. Temporal instability as a moderator of the attitude-behavior relationship. Journal of Personality and Social Psychology. 1978; 36:715-724.

Shelley KJ. Developing the American time use survey activity classification system. Monthly Labor Review. 2005; 128:3.

Silvestrini N, Gendolla GH. Automatic effort mobilization and the principle of resource conservation: One can only prime the possible and justified. Journal of Personality and Social Psychology. 2013; 104:803-816. [PubMed: 23527847]

Sivacek J, Crano WD. Vested interest as a moderator of attitude-behavior consistency. Journal of Personality and Social Psychology. 1982; 43:210-221.

Tudor-Locke C, Washington TL, Ainsworth BE, Troiano RP. Linking the American Time Use Survey (ATUS) and the Compendium of Physical Activities: Methods and rationale. Journal of Physical Activity and Health. 2009; 6:347-353. [PubMed: 19564664]

Zell E, Su R, Li H, Ho MR, Hong S, Kumkale T, Albarracin D. Cultural differences in attitudes toward action and inaction: The role of dialecticism. Social Psychological and Personality Science. 2013; $4: 511-520$. 
Table 1

Estimates of task-related effort for behavioural categories used in study 1

\begin{tabular}{lcc}
\hline ATUS category & $\begin{array}{c}\text { Average } \\
\text { MET }\end{array}$ & $\begin{array}{c}\text { Effort } \\
\text { group }\end{array}$ \\
\hline Attending sporting/recreational events & 3.64 & 1 \\
Caring for and helping household members & 1.96 & 0 \\
Caring for and helping non-household members & 2.09 & 1 \\
Consumer purchases & 2.06 & 1 \\
Eating and drinking & 1.61 & 0 \\
Education & 1.93 & 0 \\
Government services and civic obligations & 1.91 & 0 \\
HH services & 1.62 & 0 \\
Household activities & 2.92 & 1 \\
Personal care & 1.34 & 0 \\
Professional and personal care services & 1.63 & 0 \\
Religious and spiritual activities & 1.78 & 0 \\
Socializing, relaxing, and leisure & 1.60 & 0 \\
Telephone calls & 1.50 & 0 \\
Traveling & 2.33 & 1 \\
Volunteer activities & 2.22 & 1 \\
Working and work-related activities & 2.43 & 1 \\
Average & 2.03 & \\
\hline
\end{tabular}

Notes. ATUS = American Time Use Survey; MET = Metabolic equivalent of Task, estimated form Tudor-Locke et al. (2009). Effort group is 0 for ATUS categories with a MET below average and 1 for ATUS categories with a MET above average. 